\title{
The method of assessment and formation the availability of the subsystem ensuring fitness for means of transport
}

\author{
Sylwester Borowski ${ }^{1, *}$, Anna Mazurkiewicz ${ }^{1}$, and Magda Czyżewska ${ }^{1}$ \\ ${ }^{1}$ University of Science and Technology, Faculty of Mechanical Engineering, 85-796 Bydgoszcz, \\ Poland
}

\begin{abstract}
In systems of means of transport operation in order to achieve appropriate completion of assigned transportation tasks it is necessary to maintain a required number of means of transport in the state of availability for carrying out of transportation task (roadworthy and stocked). In general, the processes of rendering vehicles roadworthy are connected to supplying them with fuel and operational materials, carrying out services and repairs, condition diagnostics. In the analyzed system of transport means operation, the processes are carried out in serviceability assurance subsystem SAS. In complex operation systems, the processes of rendering technical objects roadworthy are carried out at specifically designed technical infrastructure posts. The possibility of carrying out the assigned service and repair tasks depends on the availability and the number of such posts. The article presents the method of defining the operational availability and the number of technical infrastructure posts required for appropriate functioning of assigned service and repair task. Then typical calculation results are presented in charts prepared on the basis of data obtained from tests at existing transport means operation system.
\end{abstract}

\section{Introduction}

In systems of means of transport operation in order to achieve appropriate completion of assigned transportation tasks it is necessary to maintain a required number of means of transport in the state of availability for carrying out of transportation task (roadworthy and stocked). While carrying out the transportation tasks as a result of coercive factors the exhaustion of applied potential of the means of transport takes place (they undergo damage and/or stocking is necessary). From the point of view of the efficiency of the performance of transport system, unavailable vehicles should be rendered roadworthy at a possibly shortest time. As a result, most transport systems makes use of its own technical backup area equipped with an appropriate number of stationary service and repair posts as well as mobile units. In general, the processes of rendering vehicles roadworthy are connected to supplying them with fuel and operational materials, carrying out services and repairs, condition diagnostics, transporting damaged technical objects, rearming in order to complete the assigned task. In the analyzed system of transport means operation, the processes are carried out in separate subsystem. The subsystems of the type may function properly only when appropriate availability and number of service and repair posts is granted.

The problem of control of the processes carried out at serviceability assurance subsystems from the point of view of evaluation criteria such as reliability and availability is discussed in numerous scientific publications [1, 4]. It reflects issues connected to

* Corresponding author: sylwester.borowski@utp.edu.pl 
selection of optimal strategy (policy) of servicing and repair as well as evaluation of the operation of serviceability assurance subsystems (service and repair posts). The authors of papers $[6,11]$ suggested that the methods of shaping the availability of technical backup area posts, whereas papers $[9,10]$ discuss the methods of the evaluation of the effectiveness and productivity of processes carried out at service and repair posts. Paper [3] discusses methods of defining the structure which may link posts at vehicle service systems, whereas the way of defining technically valid number of service and repair posts in transport systems was described in paper [8]. Among the many methods supporting the evaluation and control process, the semi-Markov decisive processes have been implemented [2], nondeterministic methods of defining optimal solutions (genetic algorithms, evolutionary algorithms, Monte Carlo method) [5, 7], as well as methods and models of mass service theory [12]. The objective of this paper is to work out a method of determining the number and availability of serviceability assurance subsystem post at such a level that would ensure appropriate carrying out of service and repair tasks assigned for to be carried out at such posts.

\section{Operational availability of serviceability assurance subsystem posts}

In systems of means of transport operation in order to achieve appropriate completion of assigned transportation tasks it is necessary to maintain a required number of means of transport in the state of availability for carrying out of transportation task (roadworthy and stocked). In general, the processes of rendering vehicles roadworthy are connected to supplying them with fuel and operational materials, carrying out services and repairs, condition diagnostics. In the analyzed system of transport means operation, the processes are carried out in serviceability assurance subsystem SAS. The subsystem of the type may function properly only when appropriate operational availability of service and repair posts is granted. Presented below are formulas defining operational availability of individual post of serviceability assurance subsystem.

If

$$
V_{i j}(t)=P\left(X_{i j}<t\right), i=1,2, \ldots, p, j=1,2, \ldots, q_{i}
$$

is the distribution function of serviceability time $X_{i j}$ of a single post at serviceability assurance subsystem, while

$$
W_{i j}(t)=P\left(Y_{i j}<t\right), i=1,2, \ldots, p, j=1,2, \ldots, q_{i}
$$

is the distribution function of renovation time $Y_{i j}$ of a single post at serviceability assurance subsystem (where: $p$ - number of posts groups, $q_{i}$ - number of posts of $i$-th group), then the operational availability of a single post of serviceability assurance subsystem, determined as probability that over time interval $<t, t+\tau)$ the post is available and provided for, is defined by the formula

$$
A_{O_{i j}}(t, \tau)=R_{i j}(t+\tau)+\int_{0}^{t} R_{i j}(t+\tau-x) d H_{i j}(x)
$$

where:

$R_{i j}(t)$ - the function of reliability of a single post of the serviceability assurance subsystem, $H_{i j}(t)$ - the function of renovation of a single post of serviceability assurance subsystem.

In the case, in which $t \rightarrow \infty$, the function (3) has limit value

$$
A_{O_{i j}}(\tau)=\lim _{t \rightarrow \infty} A_{O_{i j}}(t, \tau)=\frac{1}{E\left(X_{i j}\right)+E\left(Y_{i j}\right)} \cdot \int_{\tau}^{\infty} R_{i j}(x) d x
$$

where:

$E\left(X_{i j}\right)$ - the expected value of the time of serviceability of a single post of the serviceability assurance subsystem, 
$E\left(Y_{i j}\right)$ - the expected value of the time of renovation of a single post of the serviceability assurance subsystem.

\section{Operational availability of serviceability assurance subsystem}

Operational availability of serviceability assurance subsystem depends on the structure coupling the individual posts or groups of such posts. In the case of the existing system of means of transport operation the individual groups of serviceability assurance posts may be coupled in various ways. Complexity of the existing structure coupling the individual post groups depends primarily on the equipment of posts, worker qualification as well as the type of tasks to be carried out at individual post groups.

\subsection{Operational availability of posts group of serviceability assurance subsystem with a threshold structure}

Presented below are formulas defining operational availability of individual post group of a serviceability assurance subsystem in the case of the posts of the analyzed system are coupled via a threshold structure. Operational availability of $i$-th posts group consisting of $j=1,2, \ldots, q_{i}$ homogenous posts coupled by threshold structure,$k_{i}$ with $q_{i}$ " defined by formula

$$
A_{O_{i}}(t, \tau)=\sum_{c=k_{i}}^{q_{i}}\left(\begin{array}{c}
q_{i} \\
c
\end{array}\right) \cdot\left[\overline{A_{O_{i j}}(t, \tau)}\right]^{c} \cdot\left[1-\overline{A_{O_{i j}}(t, \tau)}\right]^{q_{i}-c}
$$

In the case, in which $t \rightarrow \infty$, the function (5) has limit value

$$
A_{O_{i}}(\tau)=\sum_{c=k_{i}}^{q_{i}}\left(\begin{array}{c}
q_{i} \\
c
\end{array}\right) \cdot\left[\left[E\left(\overline{X_{i j}}\right)+E\left(\overline{Y_{i j}}\right)\right] \cdot \int_{\tau}^{\infty} \overline{R_{i j}(x)} d x\right]^{c} \cdot\left[1-\left[E\left(\overline{X_{i j}}\right)+E\left(\overline{Y_{i j}}\right)\right] \cdot \int_{\tau}^{\infty} \overline{R_{i j}(x)} d x\right]^{q_{i}-c}
$$

\subsection{Operational availability of serviceability assurance subsystem with a serial structure}

The general instance is connected to the situation involving individual serviceability assurance subsystem groups, due to specialist equipment as well as worker qualifications may not replace each other and are supposed to carry out tasks of various type and range. Thus, the post groups of serviceability assurance subsystem are coupled by serial structure. Then, operational availability of serviceability assurance subsystem is determined as product of the availability of its individual groups:

- over time interval $<t, t+\tau$ )

$$
A_{O}(t, \tau)=\prod_{i=1}^{p} A_{O_{i}}(t, \tau)
$$

- in the case, in which $t \rightarrow \infty$

$$
A_{O}(\tau)=\prod_{i=1}^{p} A_{O_{i}}(\tau)
$$

\section{Operational availability of the serviceability assurance subsystem in carrying out the assigned task}

Operational availability of the serviceability assurance subsystem is understood as capability to carry out the assigned service and repair task. Each task assigned to SAS is determined by the length of the time interval $\tau$ devoted to the completion of the task, the size of the task (how many technical objects should be rendered roadworthy and/or stocked) as well as the scope of the task (what should be done). The measure of operational availability of SAS posts in carrying out of the assigned task is the product of the probabilities of two events taking place: 
- the event of SAS posts being available at any point (roadworthy and stocked) to undertake the assigned task and will remain in this condition for the time interval $\tau$ of the task duration; this probability is expressed through the value of operational availability of the analyzed subsystem,

- the event of the task assigned at the posts of the subsystem in question will be carried out, i.e. in the time interval $\tau$ the number of objects rendered technically roadworthy will be higher than $k$; this probability is expressed through the value of the productivity index of SAS posts (the way of defining the productivity index is presented in paper [10]).

Taking the above discussion into consideration, the operational availability of the serviceability assurance subsystem in carrying out the assigned service and repair task in the time interval $\tau$, is defined as follows

$$
A_{O Z}^{(k)}(\tau)=A_{O}(\tau) \cdot Z^{(k)}(\tau)
$$

where:

$A_{O}(\tau)$ - operational availability of the posts of SAS defined as the probability of this subsystem being available at any point $t$ and remaining in this condition over a required time interval $\tau$,

$Z^{(k)}(\tau)$ - probability of the number of technical objects rendered roadworthy at SAS posts in the time interval $\tau$ being bigger than $k$.

\section{Required availability of the serviceability assurance subsystem in carrying out the assigned task}

Required operational availability of the SAS for carrying out of service and repair task (rendering $k$ number of technical objects roadworthy in the time interval of $\tau$ length), determined as product of required availability $A_{O_{r e q}}^{(k)}(\tau)$ as well as the required value of productivity index $Z_{r e q}^{(k)}(\tau)$ for analyzed posts in the time interval of $\tau$ length is realized in the formula

$$
A_{O Z_{\text {req }}}^{(k)}(\tau)=A_{O_{\text {req }}}^{(k)}(\tau) \cdot Z_{\text {req }}^{(k)}(\tau)
$$

Service and repair task assigned to the SAS is determined by the required number $k$ of technical objects which should be rendered roadworthy and/or stocked in the given time interval of $\tau$ length, at posts for this subsystem. Whereas the required availability $A_{O_{r e q}}^{(k)}(\tau)$ of SAS determined for number $k$ of technical objects rendered roadworthy in the time interval of $\tau$ length is described as follows

$$
A_{O_{r e q}}^{(k)}(\tau)=\frac{T_{r e q}^{(k)}(\tau)}{T_{r e q}^{(k)}(\tau)+U_{r e q}^{(k)}(\tau)}
$$

where:

$T_{r e q}^{(k)}(\tau)$ - required availability time for SAS posts for given $k$ and $\tau$,

$U_{r e q}^{(k)}(\tau)$ - required unavailability time for SAS posts for given $k$ and $\tau$.

Assuming that for any time interval of $\tau$ length the sum of required availability and unavailability times for SAS equals the time interval of $\tau$ length, i.e. $T_{r e q}^{(k)}(\tau)+U_{r e q}^{(k)}(\tau)=\tau$, then formula (11) may be written as follows

$$
A_{O_{\text {req }}}^{(k)}(\tau)=\frac{T_{r e q}^{(k)}(\tau)}{\tau}
$$


Required availability time $T_{r e q}^{(k)}(\tau)$ for SAS posts depends on the anticipated total time of rendering $k$ number of technical objects (transport means) roadworthy in the time interval of $\tau$ length as well as the $q$ number of uniform posts of the analyzed subsystem (parallel channels for rendering roadworthiness) and is described by the condition

$$
T_{r e q}^{(k)}(\tau)=\frac{k \cdot \overline{U^{O T}}(\tau)}{q} \leq \tau
$$

where

$\overline{U^{O T}}(\tau)$ - mean time of technical object remaining at SAS (mean time of rendering technical objects roadworthy).

When $T_{r e q}^{(k)}(\tau)>\tau$, then in the time interval for the posts of the analyzed subsystem the rendering of the required $k$ number of technical objects roadworthy is not possible.

Evaluation of operational availability of serviceability assurance subsystem SAS for carrying out the assigned task consists of determining the value of actual availability of the subsystem (for the required time interval of $\tau$ length as well as required $k$ number of technical objects which should be rendered roadworthy and/or stocked) and then comparing to the value of required availability the SAS should has in order for the assigned task to be carried out according to the relation

$$
A_{O Z}^{(k)}(\tau)=A_{O}(\tau) \cdot Z^{(k)}(\tau) \geq A_{O Z_{r e q}}^{(k)}(\tau), \text { for } k \geq k_{r e q}(\tau)
$$

If the value of operational availability of the SAS posts for carrying out the assigned task is lower than required, the assigned task at SAS posts may not be carried out properly (in the time interval of $\tau$ length it is not possible to render the required number $k_{\text {req }}(\tau)$ of technical objects roadworthy). The presented method makes it possible to analogically determine and evaluate the availability for carrying out the assigned service and repair task for both a serviceability assurance subsystem, group of posts or an individual post.

\subsection{Determining the required availability of posts of the serviceability assurance subsystem in carrying out the assigned task}

In the case of the serviceability assurance subsystem comprise $i=1,2, \ldots, p$ of groups containing $j=1,2, \ldots, q_{i}$ of posts linked to a given structure, it is possible to determine the required availability of posts at individual groups. Assuming that the $i$-th group comprises uniform posts are liked by threshold structure, the required availability of posts is assigned

$$
A_{i j}=A_{i j_{\text {req }}} \Leftrightarrow A_{O_{i}}(\tau)=\sum_{c=k_{i}}^{q_{i}}\left(\begin{array}{c}
q_{i} \\
c
\end{array}\right) \cdot\left[A_{i j}\right]^{c} \cdot\left[1-A_{i j}\right]^{q_{i}-c} \geq A_{O_{i_{\text {req }}}}(\tau)
$$

Figures 1 and 2 present values of required availability of posts at $i$-th group of serviceability assurance subsystem, determined in relation with number of posts of the $i$-th group as well as the value of parameters determining the assigned service and repair task (number of objects as well as the time of rendering them roadworthy). 


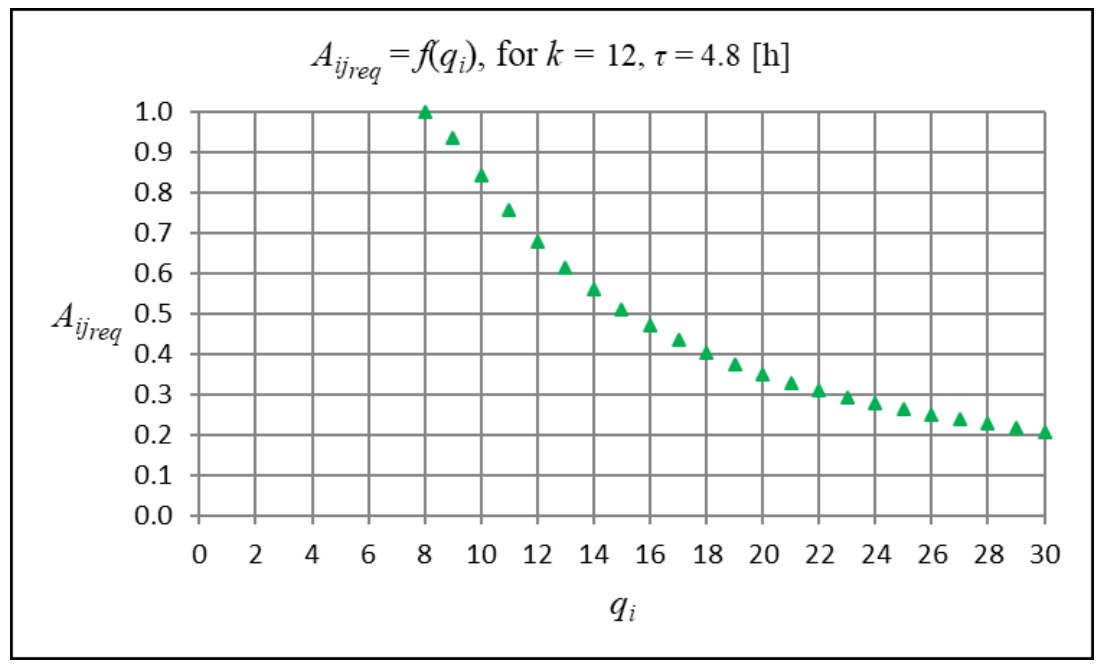

Fig. 1 Required availability of individual post of functions of the number posts of the $i$-th group.

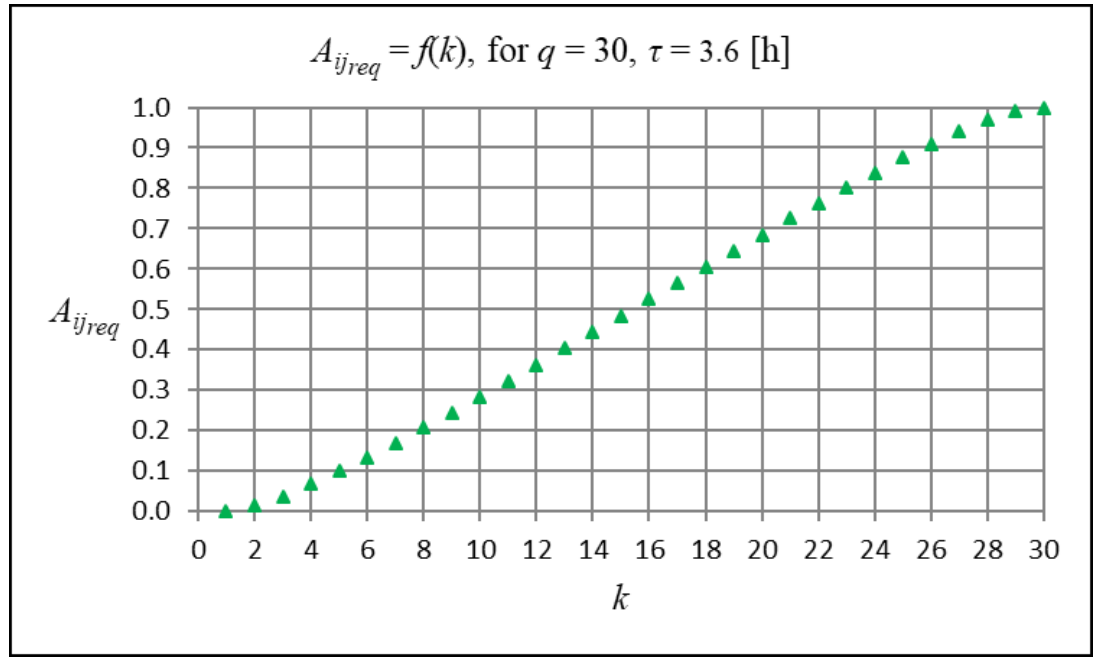

Fig. 2 Required availability of individual post of functions of the number of objects rendered roadworthy.

\subsection{Determining the required number of posts of the serviceability assurance subsystem in carrying out the assigned task}

In the case of the serviceability assurance subsystem comprise $i=1,2, \ldots, p$ of groups containing $j=1,2, \ldots, q_{i}$ of posts linked to a given structure, it is possible to determine the required number of posts at individual groups. Assuming that the $i$-th group comprises uniform posts are liked by threshold structure, the required number of posts is assigned

$$
q_{i}=q_{i_{\text {req }}} \Leftrightarrow A_{O_{i}}(\tau)=\sum_{c=k_{i}}^{q_{i}}\left(\begin{array}{c}
q_{i} \\
c
\end{array}\right) \cdot\left[A_{i j}\right]^{c} \cdot\left[1-A_{i j}\right]^{q_{i}-c} \geq A_{O_{i_{\text {req }}}}(\tau)
$$

Figures 3 and 4 present values of required number of posts at $i$-th group of serviceability assurance subsystem, determined in relation with availability value $G_{i j}$ of individual post of the $i$-th group as well as the value of parameters determining the assigned service and repair task (number of objects as well as the time of rendering them roadworthy). 


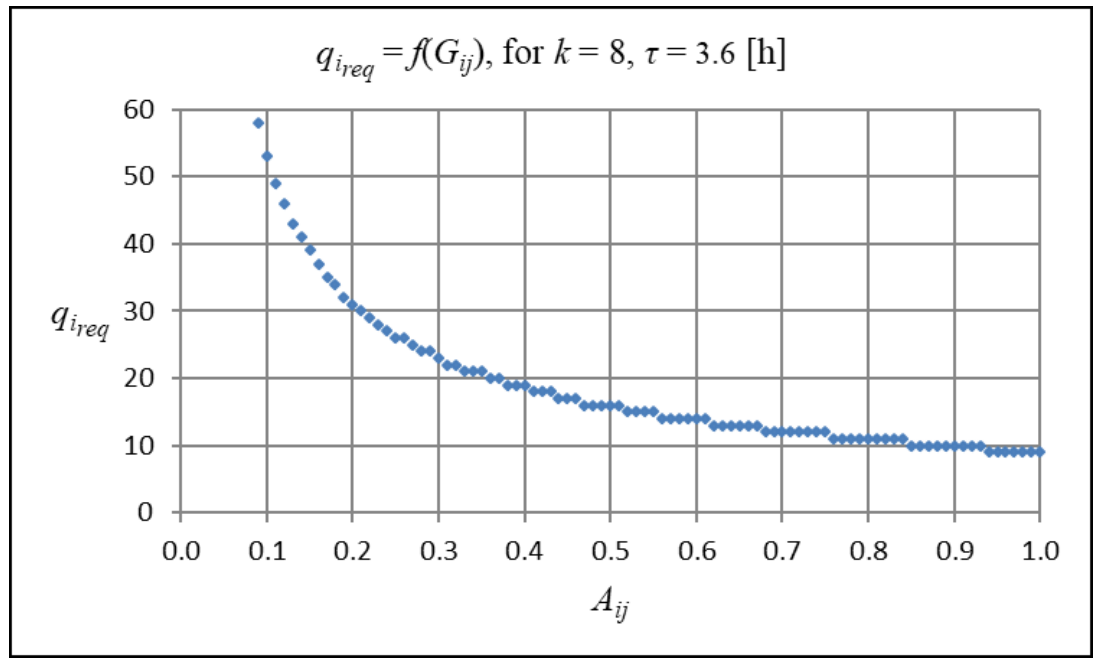

Fig. 3 Required number of posts of the $i$-th group in the functions of availability of individual posts.

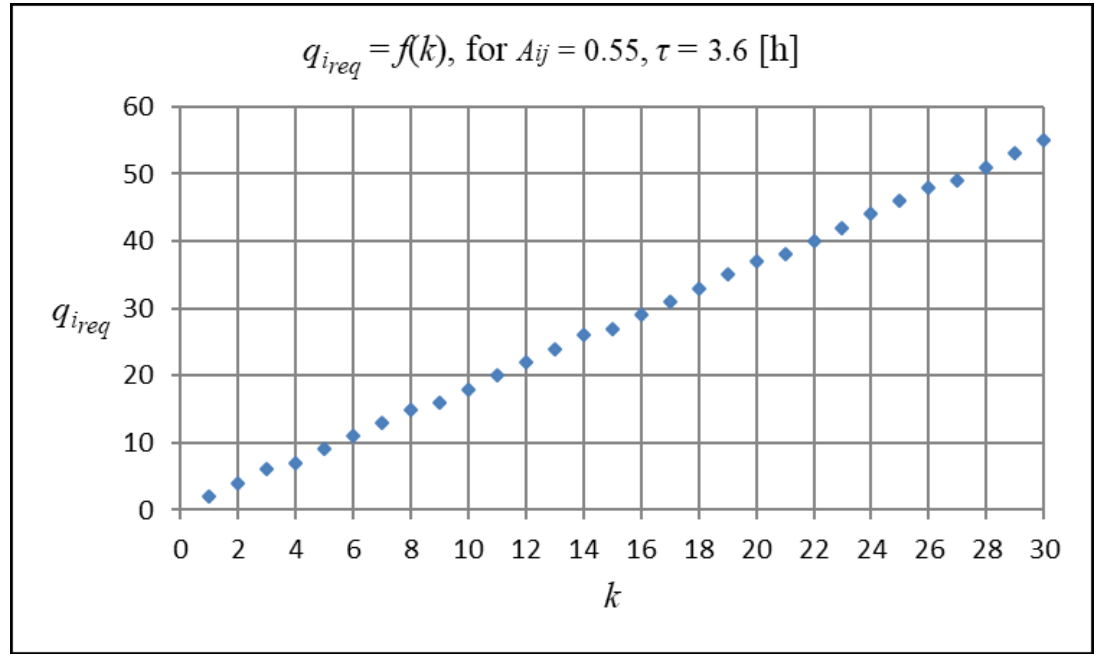

Fig. 4 Required number of posts of the $i$-th group in the functions of number of objects rendered roadworthy.

\section{Summary}

On the basis of the method presented in the paper, it is possible to select (determine) the minimum required number and availability of posts of serviceability assurance subsystem so that the assigned service and repair tasks are carried out properly. It is completed on the basis of the selected criteria for evaluation when actual availability of serviceability assurance subsystem equals at least the required availability, e.g. for the number of objects rendered roadworthy $k=8$, time of rendering roadworthy $\tau=3.6[\mathrm{~h}]$ and individual post availability $A_{i j}=0.8$, required number of posts of $i$-th group amounts to $q_{i_{\text {req }}}=11$, then $A_{O_{i}}(\tau)=0.795 \geq A_{O_{\text {ireq }}}(\tau)=0.762$ (Figure 3).

The presented method may be utilized in order to evaluate operational availability of an individual post as well as a group of posts of a given type coupled with an appropriate 
structure or a serviceability assurance subsystem consisting of various types of posts. Providing the required availability of serviceability assurance subsystem is possible due to:

- adjusting the number and structure of service and repair posts,

- adjusting the equipment at posts in order to, when necessary, facilitate carrying out of particular tasks at posts in various groups,

- implementation of posts (devices and tools) of higher reliability, durability, and productivity.

\section{References}

1. D-Y. Chen, K. S. Trivedi, Closed-form analytical results for condition-based maintenance (Reliability Engineering and System Safety, Elsevier), (2002)

2. D-Y. Chen, K. S. Trivedi, Optimization for condition-based maintenance with semiMarkov decision process (Reliability Engineering and System Safety, Elsevier), (2005)

3. A. Gołąbek, Metoda określania struktury systemu obstugi pojazdu samochodowego (Zagadnienia Eksploatacji Maszyn), (1984)

4. L. Knopik, K. Migawa, Optimal age-replacement policy for non-repairable technical objects with warranty (Eksploatacja i Niezawodność - Maintenance and Reliability), (2017)

5. M. Marseguerra, E. Zio, Optimizing maintenance and repair policies via a combination of genetic algorithms and Monte Carlo simulation (Reliability Engineering and System Safety, Elsevier), (2000)

6. K. Migawa, The evaluation of availability of the serviceability assurance subsystem posts (Journal of KONBiN), (2012)

7. K. Migawa, L. Knopik, S. Wawrzyniak, Application of genetic algorithm to control the availability of technical systems (Engineering Mechanics, Institute of Thermomechanics Academy of Sciences of the Czech Republic), (2016)

8. J. Okulewicz, Z. Smalko, Wyznaczanie technicznie uzasadnionej liczby stanowisk obshugowo-naprawczych (Instytut Transportu Politechniki Warszawskiej), (1988)

9. M. Szubartowski, Efficiency of repairs performed within the emergency repair subsystem of municipal bus transportation system (Journal of KONES Powertrain and Transport), (2012)

10. M. Woropay, K. Migawa, P. Bojar, The model of defining the efficiency of logistics subsystem posts in the transport system (Journal of KONES Powertrain and Transport), (2010)

11. M. Woropay, J. Żurek, K. Migawa, Model oceny $i$ ksztattowania gotowości operacyjnej podsystemu utrzymania ruchu $w$ systemie transportowym (Instytut Technologii Eksploatacji, Radom), (2003)

12. JK. Vaurio, On time-dependent availability and maintenance optimization of stanby units under various maintenance policies (Reliability Engineering and System Safety, Elsevier), (1997) 